\title{
Quake panel admits prediction is 'difficult'
}

[TOKYO] The government committee responsible for overseeing Japan's earthquake prediction programme has approved a report by seismologists that clearly admits for the first time that earthquake prediction is difficult.

In the particular case of the expected Tokai earthquake near Tokyo, on which much of Japan's prediction efforts have focused, the review says that prediction will be possible only in a complex set of circumstances that are unlikely to be met.

The report is being widely interpreted in the Japanese media as admitting that earthquake prediction is virtually impossible. But government agencies involved in the research, as well as leading politicians, seem determined that the prediction programme should continue. The programme employs hundreds of researchers on an annual budget of more than $¥ 20$ billion (US\$185 million) and has run for 30 years.

The report was put together by various subcommittees of the Geodetic Council, an advisory body to the Ministry of Education, Science, Sports and Culture made up of astronomers and Earth and space scientists.

These subcommittees were composed primarily of seismologists working on the programme. An external panel of scientists not involved in the research also produced comments on a draft of the report.

The report, which was approved by the full council last week, concludes that predicting the time, location and magnitude of earthquakes is, in general, koonan ("difficult"). The word has connotations of being almost impossible. But its meaning is ambiguous - allowing government agencies and researchers to justify continued research on prediction.

Huge investments have been made in setting up dense observation networks in the Tokai region around the Izu peninsula, as researchers have predicted that a major earthquake can be expected in the near future. A committee of six 'wise men' can be called in by the meteorological agency at any time to examine seismic data that might indicate that an earthquake is imminent, and advise the prime minister to issue a warning.

The leaders of the programme have always maintained that prediction of the Tokai earthquake is possible, and this has provided much of the justification for their work. Their confidence was based in part on the belief that the Tonankai earthquake of magnitude 7.9 that occurred in the same region in 1944 showed clear precursors that could have acted as a warning.

But the quality of observation data in 1944 was limited, and much of the 30-year programme has been spent collecting empirical data in the hope of finding clear-cut precursors of earthquakes.

The new review for the first time places severe limitations on the possibility of predicting the Tokai earthquake, however, by stating that, if prediction is to be possible, crustal motions preceding the earthquake must be of the same type and follow the same time dependence and amplitude as the Tonankai earthquake.

In all other circumstances, prediction of the Tokai earthquake will be "difficult", the review says, adding that no estimate can be given of the likelihood that the required conditions will be met.

For the first time in the history of the programme, the report accepts that there is a "huge gap" between the public's perception of researchers' ability to predict earthquakes and the present level of the science. It calls for the "difficulties" of earthquake prediction to be made "widely known" to the public, which has become disillusioned with the science since the Kobe earthquake of 1995 which caught the public completely by surprise. It also calls for greater efforts in disaster mitigation.

Despite such admissions, the government agencies backing the programme have expressed their determination to carry on with the research. The chief cabinet secretary, Seiroku Kajiyama, has said: "It is a matter of course that the government should continue efforts [to predict earthquakes] if there is a possibility of earthquake prediction in the future".

DavidSwinbanks

\section{German law could boost prospects for organ transplants}

[MUNICH] The number of organ donors in Germany may soon increase following a decision last week by the Bundestag, the lower house of the federal parliament, to approve a controversial bill regulating organ transplants.

The bill, which has had a five-year struggle, is expected to be approved by the upper house, the Bundesrat, in the next few weeks. It gives legal status to a practice that has in fact been carried out in Germany for many years.

The long debate about the law is due to Germany's extreme sensitivity on any bioethical issue, a reaction to the country's Nazi past. Opponents fear that organs could be removed from people who are still alive.

The German Chamber of Physicians first drew up a protocol for organ transplants in 1982. That, in line with other European countries, defined death as the moment at which the brain ceases to function.

But efforts to formalize this in law, begun in the early 1990s, led to an emotional debate in which critics from all political parties argued that death should be defined as the moment at which the heart also stops beating. As a result of the controversy, the number of organ donors fell by 10 per cent.

The new law does little more than confirm present organ transplantation practice, which is slightly more conservative than elsewhere in Europe. Organs may be removed from a donor at the moment of total brain death, rather than after brainstem death, which many countries accept as the first irreversible event of death.

Brain death must be confirmed by two independent doctors. Previous 'informed consent' from the donor, through a standard donor-card system, or through verbal or written consent in hospital, is required. In its absence, a relative or partner may give consent, but may not contradict any known wishes of the donor. Only close relatives of a patient, or a spouse, may donate kidneys as live donors. The sale of organs is banned.

Organ allocation will still be the task of Eurotransplant, the Netherlands-based office, which uses a single database to allocate organs from its five member countries - Germany, the Netherlands, Austria, Belgium and Luxembourg.
Bernard Cohen, director of Eurotransplant, which allocates 5,000 organs a year but which has a waiting list of 15,000 , says the greater public confidence resulting from the new law might increase organ donations slightly, or at least lower the refusal rate.

But he says he would not expect a large increase in the number of donors, because the requirement for informed consent has a restricting effect. The two members of Eurotransplant with the lowest per capita rate of organ donation are the Netherlands and Germany, which both require informed consent, he says.

According to Ludger Honnefelder, director of the Bonn Institute for Science and Ethics, the law has been carefully drafted to avoid directly equating death with brain death to side-step the problem of what 'alive' really means.

Reflecting continued memory of Nazi practices, the proposed law states in two separate paragraphs that organs may not be removed until death is observed and that organs may not be removed before total brain death is registered. 